\title{
Criterios para establecer el ámbito de aplicación del Nuevo Estatuto del Consumidor
}

\author{
Criteria for establishing the scope of the application of the New \\ Consumer Statute
}

\begin{abstract}
RESUMEN
La relación de consumo es el criterio que determina el ámbito de aplicación del Nuevo Estatuto del Consumidor, a pesar de ello, el Nuevo Estatuto no definió la relación de consumo, pero sí definió los conceptos que permiten delimitar la existencia de una relación de consumo como supuesto de hecho normativo: consumidor, proveedor, productor y producto. Establecer el ámbito de aplicación de la nueva normativa de consumo es importante porque ofrece ventajas comparativas con respecto a la normativa contenida en el Código de Comercio y reconoce la vulnerabilidad del consumidor como eslabón débil de la cadena de consumo, de tal manera este trabajo busca reflexionar sobre cada uno de los elementos enunciados y su aplicabilidad.
\end{abstract}

\section{PALABRAS CLAVE}

Derecho del consumo, Consumidor, Proveedor, Productor, Producto.

\section{ABSTRACT}

The relation of consumption is the criterion that determines the scope of application of the New Consumer Statute, despite this, the New Statute did not define the relation of consumption, but it did define the concepts that allow to delimit the existence of a relation of consumption as normative assumption: consumer, supplier, producer and product. Establishing the scope of the new consumer regulation is important because it offers comparative advantages regarding the regulations contained in the commercial code and recognizes the vulnerability of the consumer as a weak link in the consumer chain, so this work seeks to reflect on each of the elements announced and their applicability.

\section{KEYWORDS}

Right of consumption, Consumer, Supplier, Producer, Product.

\section{RAFAELA SAYAS CONTRERAS}

Abogada. Docente investigadora de la Universidad de Cartagena. Directora del Grupo de Investigación Conflicto y Sociedad de la Universidad de Cartagena. Máster en Derecho por la Universidad Nacional de Colombia. Ph.D. en Sociología por la Universidad de Belgrano, Buenos Aires (Argentina). rafaelaester@gmail.com

\section{JESÚS DANIEL TOVÍO FLÓREZ}

Abogado de la Universidad de Cartagena. Joven investigador patrocinado por Colciencias, adscrito al Grupo Conflicto y Sociedad de la Facultad de Derecho de la Universidad de Cartagena. jesus-tovio@hotmail.com 


\section{INTRODUCCIÓN}

El presente artículo representa un avance de una investigación más amplia que actualmente se está desarrollando al interio de la línea de derecho privado del Grupo de Investigación Conflicto y Sociedad de la Universidad de Cartagena, en el marco del Proyecto denominado "El acceso a los derechos subjetivos de consumidores y víctimas, una perspectiva desde los derechos humanos en el marco de la Constitución de 1991", que tiene como propósito analizar el contexto institucional, jurídico y social de acceso a los derechos subjetivos de consumidores y víctimas en el derecho interno colombiano de conformidad con la Constitución de 1991 y las normativas de la Organización de Naciones Unidas, en el marco de los derechos humanos.

Delimitar el ámbito de aplicación del Estatuto del Consumidor reviste importancia para la defensa de los derechos de los consumidores. Los derechos patrimoniales de los consumidores están comprendidos por las relaciones de consumo que se establecen en el mercado entre los consumidores y los proveedores $\mathrm{y} / \mathrm{o}$ productores. Por mucho tiempo, estas relaciones de consumo fueron reguladas por la legislación comercial, lo que no brindaba una protección eficaz a los derechos de los consumidores por cuanto el derecho comercial está diseñado para proteger los intereses de los productores y proveedores, quedando relegado normativamente la figura del consumidor. En la expedición un nuevo estatuto que regula el derecho de consumo, con sus elementos que le son característicos, es necesario comprender los elementos que determinan una relación de consumo para a partir de allí tener claridad sobre la aplicabilidad de la nueva normativa. El objetivo principal desarrollado en este trabajo es abordar el análisis de los concepto de consumidor, proveedor y productor como elementos de la relación de consumo necesarios para definir el criterio de delimitación en la aplicación de la Ley 1480 de 2011; se desarrolló una investigación jurídica, analítica, descriptiva, de carácter documental abordada a nivel dogmático-teórico, partiendo del análisis de información secundaria recopilada en matrices de datos, trabajada través del análisis documental de la siguiente pregunta problema: ¿Cuáles son los criterio jurídicos para establecer el ámbito de aplicación de la Ley 1480 de 2011 o Nuevo Estatuto del Consumidor? Para tales efectos nos ceñiremos al siguiente orden metodológico:

Primero se hará mención de la relación de consumo y su consagración en el Nuevo Estatuto del Consumidor, seguido se abordará el estudio del concepto de consumidor y cómo se ha concebido al consumidor en el ordenamiento jurídico colombiano, y por último se abordarán los conceptos de proveedor productor y se plantearán las conclusiones.

\section{Relaciones comerciales y relación de consu-}

Para determinar el alcance o la esfera que pretende abarcar el Estatuto del Consumi- dor, es necesario determinar la relación que da origen a la necesidad de protección, siendo esta, la relación de consumo.

La relación de consumo reviste de mucha mportancia a la hora de delimitar el ámbito de aplicación del Estatuto del Consumidor Este ha sido uno de los temas más polémicos y controvertidos del nuevo Estatuto, por cuanto muchos doctrinantes han entendido que dicho ámbito de aplicación comprende a gran mayoría de las relaciones comerciales actuales, es decir, la inmensa mayoría de tráfico mercantil se regularía por el nuevo Estatuto del Consumidor, dejando las disposiciones del Código Civil y las del Código de Comercio con aplicabilidad solo en las relaciones jurídicas que se den entre dos comerciantes o dos particulares, sin que exista entre ellos una relación de consumo.

Pero como veremos, existen relaciones jurídicas a las cuales no se les aplicaría el Estatuto del Consumidor, por cuanto no revisten el carácter de relación de consumo. Esas reaciones que quedan por fuera del ámbito de aplicación del Estatuto del Consumidor son las relaciones jurídicas estrictamente comerciales o empresariales, cuya finalidad es incorporar los bienes que se adquieren de nuevo a la cadena de producción, transformarlos n otro bien o servicio o para suministrárselos a otro quien será en últimas el que adquiera, use o disfrute el producto final.

De esta manera, por ejemplo, si un supermer- El artículo 2 de la Ley 1480 de 2011 señala su cado celebra un negocio jurídico de compra- objeto y ámbito de aplicación. 
ARTíCULO 20. OBJETO. Las normas de esta ley regulan los derechos y las obligaciones surgidas entre los productores, proveedores y consumidores y la responsabilidad de los productores y proveedores tanto sustancial como procesalmente.

Las normas contenidas en esta ley son aplicables en general a las relaciones de consumo y a la responsabilidad de los productores y proveedores frente al consumidor en todos los sectores de la economia respecto de los cuales no exista regulación especial, evento en el cual aplicará la reguación especial y suplementariamente las normas establecidas en esta Ley.

Esta ley es aplicable a los productos nacionales e importados.

Este artículo determina las relaciones jurídicas cuya regulación es el objeto de la mencionada ley. Esto para fijar el ámbito de aplicación del Estatuto del Consumidor y así, separar su aplicación con respecto a otras normas que regulan conductas contenidas en el Código Civil y el Código de Comercio.

Como primera medida señala que esta ley regulará los derechos y obligaciones surgidas entre productores, proveedores y consumidores, así como la responsabilidad de los productores y proveedores tanto en lo sustancial como en lo procesal. Este último enunciado, aclara las dudas que existían sobre el régimen de responsabilidad aplicable en las relaciones de consumo, pues se establece en este artículo que las reglas sobre responsabilidad de productores y proveedores son las dictadas en el Estatuto del Consumidor y no las del Derecho Civil y Comercial, y en lo procesal, en los litigios en los que se busca establecer responsabilidades de productores o proveedores, se observarán en primera medida las disposiciones de la Ley 1480 de 2011.

A renglón seguido contempla expresamente la responsabilidad de los productores y proveedores tanto sustancial como procesalmente, enunciado con el que son claras dos cosas: la primera, que las reglas de responsabilidad de los productores y proveedores son las previstas el Estatuto indicando que el régimen de responsabilidad en protección al consumidor se aparta de las reglas de las no mativas generales -civil y comercial-; y la segunda, que los procedimientos relativos se sujetarán a lo dispuesto en la Ley 1480 de 2011 y no en las normativas generales -Códigos de Procedimiento Civil y Contencioso Administrativo- (Giraldo, Caicedo \& Madriñán, 2012, p.6).

Este artículo trae algo novedoso e importanestablecer el ámbito de aplicación del Estatuto del Consumidor, el cual es la mención que hace de la relación de consumo. Según Villalba (2012), “En este artículo aparece por primera vez en una ley la expresión relación de consumo" (p.219). Aunque el Estatuto del Consumidor no define la relación de consumo, sí define los sujetos que intervienen en ella, los cuales se estudiarán más adelante.
La legislación colombiana sobre derecho de consumo no hacía referencia alguna, en ninguna norma, a la relación de consumo, es decir, no existía un fundamento legal de esta noción jurídica. Sería la Superintendencia de Industria y Comercio, entidad encargada de proteger a los consumidores, la que hiciera alusión en sus conceptos a la relación de consumo, con el fin de delimitar el ámbito de aplicación de las normas de protección a consumidor a dichas relaciones.

La Superintendencia de Industria y Comercio (SIC) definió la relación de consumo como "Ia que se presenta entre el productor, proveedor o expendedor y el consumidor" (Concepto 03025237 del 09 de mayo de 2003).

La Ley 1480 de 2011, tampoco consagró un definición de la relación de consumo, aunque sí hace mención en su artículo 2 como se anotó en las líneas precedentes y en su artículo 5 se encuentran las definiciones que permiten delimitar su concepto, así lo expresan Giraldo, Caicedo y Madriñán (2012):

Conforme al Estatuto del Consumidor la relación de consumo es el criterio que define el ámbito de aplicación de sus normas; que constituye una categoría juridica que determina la aplicación de esta normatividad específica de consumo. Sin embargo, en el artículo 5 del Estatuto, Definiciones, encontramos los enunciados que permiten delimitar el concepto de relación de consumo. Son ellos: los sujeproveedor o expendedor; el objeto: pro- ductos; las transacciones o modos de la relación de consumo: adquirir, disfrutar o usar; y, los roles de mercado: destinatario final y profesionalidad (pp.31,32).

El artículo 5 del Nuevo Estatuto del Consumidor establece un listado de 17 definiciones de palabras o expresiones; consideramos que las más importantes son las de los numerales $3,8,9$ y 11 del citado artículo, pues en esos numerales se recogen los criterios que la Corte Suprema de Justicia

y la SIC han expuesto sobre esas expresiones o conceptos; conceptos además que son de mucha importancia por cuanto aluden los sujetos que intervienen en la relación de consumo y esta última, delimita el ámbito de aplicación de las normas de protección al consumidor.

Esas expresiones son las de consumidor, productor, proveedor y producto; de las cuales nos ocuparemos a continuación.

\section{Consumidor}

Esta noción, ha sido quizás el elemento más complicado de la relación de consumo en delimitar, varía en los diferentes ordenamientos jurídicos, es decir, no existe una noción única ni uniforme de consumidor en el Derecho Comparado.

En el ámbito comunitario europeo no se acepta como consumidor a las personas jurídicas, en algunas legislaciones como la mexicana, la peruana o la costarricense se ha cobijado al pequeño empresario 
como consumidor a pesar de actuar dentro del ámbito de su actividad profesional. (...). En el contexto del Mercosur la definición comunitaria de consumidor y las definiciones legales de estados miembros hacen expresa mención a la relación de consumo. Esta última posición refuerza la importancia de la relación de consumo como elemento delimitador de aplicación del derecho del consumo (Villalba, 2012, p.112)

Doctrinalmente existe una concepción amplia y otra restringida de la noción de consumidor. Según la concepción amplia, consumidor es toda persona que contrate la adquisición, utilización o disfrute de un bien o la prestación de servicio, para la satisfacción de sus necesidades domésticas o profesionale y para la concepción restringida, consumidor es solo la persona que contrata la adquisición, utilización o disfrute de un bien o la prestación de un servicio para satisfacer sus necesidades personales, familiares o domésticas. Velilla (como se citó en Ossa, 2010), lo explica de esta manera:

Existe una concepción amplia y otra restringida de la noción de consumidor. Según la primera acepción, el consumido es toda persona que contrata con el fin de consumir, es decir, utilizar un bien o servicio; por lo que si se acoge esta acepción consumidor no será únicamente quien contrata para su uso personal, sino también quien lo hace para su uso profesional, siendo así cada eslabón de la cadena de producción un consumidor del producto de su antecesor. Según la acepción restringida, consumidor es quien contrata con fin de utilizar el bien o servicio adquirido para satisfacer sus necesidades personales o familiares; por lo que, de acoger est acepción, quedan excluidos quienes contratan para fines profesionales, y no sim plemente personales o familiares (p.208).

El Decreto 3466 de 1982, antiguo Estatuto del Consumidor, acogió la concepción amplia de consumidor, al definirlo como toda persona, natural o jurídica, que contrate la adquisición, utilización o disfrute de un bien o la prestación de un servicio determinado para la satisfacción de una o más necesidades. Esta definición de consumidor fue interpretada en varias ocasiones por la Superintendencia de Industria y Comercio y la Corte Suprema de Justicia, por cuanto establecía un concepto bastante amplio de consumidor, que implicaba que consumidor era todo aquel que celebre un contrato o todo aque que contrata con el fin de consumir. Al respecto, Echeverri, Arango, Mesa, Peláez, Campillo y Ramírez (2012) afirman:

Este es un concepto bastante amplio, que lleva al supuesto inadmisible de que consumidor es todo sujeto que celebre un contrato, pues el derecho de consumo nace de la necesidad de brindar protección en una relación jurídica en la que predomina la desigualdad, y se aplica únicamente en los casos donde se identifique existencia de una relación de consumo (p.8)
Fue la Superintendencia de Industria y Comercio, a través de sus conceptos, la que empezó a delimitar la noción de consumidor. Para establecer quién es consumidor, la SIC parte de la finalidad del contrato o el objeto que llevó a contratar, pues si una persona contrata para incorporar en el proceso productivo no es consumidor, sino productor algo que resultaría ilógico por cuanto en la relación de consumo tiene que haber dos partes que son consumidores y productores.

También aludió a la desigualdad que existe en las relaciones entre consumidores y productores, la cual es presupuesto para que exista una relación de consumo, relación que a su vez se fundamenta en la diferencia de conocimientos entre los extremos de dicha relación, razón por la cual la ley busca proteger los intereses del que tenga menos conocimiento o carezca de profesión. En concepto del año 1996, la SIC afirmó:

Importa entonces la finalidad perseguida por el adquiriente o usuario, y si este adquiere el bien o el servicio para incorporarlo en un proceso productivo, o para transformarlos y colocarlo posteriormente en el mercado, no tendría respecto de esa operación de adquisición la calidad de consumidor; allí ostenta la calidad de "productor", según la definición que trae el Decreto 3466 de 1982. Pero si el adquiriente del bien o servicio lo coloca nuevamente en el mercado, sin transformarlo $n$ incorporarlo en un proceso productivo, $y$ no se sirve del mismo para la satisfacción de una necesidad personal, ese adqui- riente tendrá la calidad de "proveedor", a la luz del citado Decreto (...). En efecto, en las relaciones consumidor-productor o consumidor-proveedor, se establecen vínculos entre un profesional y un lego, o no profesional, con lo cual el ordenamiento busca particularmente proteger los intereses del primero, toda vez que es la parte económica más débil y se encuentra en una posición más frágil, en la medida en que no tiene los conocimientos de un profesional, como lo es el productor o el proveedor. En las relaciones de estos últimos no existe esa disparidad, por cuanto ambos son "profesionales" $y$, por ende, se encuentran, al menos jurídicamente, en condiciones de igualdad (Concepto No. 96027242 de septiembre 2 de 1996).

En el año 2001, la SIC se aleja del criterio de destinatario final, como presupuesto para definir quién es consumidor, y lo sustituye por el de la existencia de desigualdad o desequilibrio entre los sujetos partes en las relaciones de consumo; existe ese desequilibrio cuando el consumidor actúa por fuera de su esfera profesional, lo cual lo hace estar menos informado que el productor y proveedor y ponerlo en desventaja o desequilibrio con respecto a aquellos, lo que implica que el consumidor también puede ser profesional.

Nótese cómo la definición anteriormente citada no señala que la utilización o disfrute que el consumidor efectúe se refiera al uso final que se le deba dar a los mismos. En este punto es clara la diferencia positiva entre la normatividad colombiana y la 
tendencia legislativa a nivel suramericano, pues es evidente que estas legislaciones extranjeras son claras cuando excluyen de la categoría de consumidor a todos aquellos que en principio participen de la cadena de elaboración y producción de un bien o servicio, sin efectuar el uso o consumo final del mismo (...). En efecto, la definición de consumidor del Decreto 3466 de 1982 deja por fuera el concepto de destinatario final del producto, entendida esta noción en un sentido económico, es decir, consumidor final presupone que este, con el acto de consumo, atienda una necesidad propia, pero no el desenvolvimiento de una actividad negocial propia de quie celebra la relación de consumo (...). En este sentido, nuestro máximo tribuna constitucional no hizo distinción algun cuando se pronunció sobre la protección de las relaciones de consumo, es decir, no condicionó la órbita de protección que tienen los consumidores a la característica de usuarios finales de un determinado bien o servicio, aunque sí mencionó que en las relaciones de consumo existe una desigualdad manifiesta entre las partes, $y$ que son esas relaciones donde se presena desequilibrio económico las que Constitución Política, en su Artículo 78, in dica proteger. Así las cosas, podemos concluir que las normas de protección al consumidor sí pueden aplicarse para aquellas personas naturales o jurídicas que hayan tilizado, transformado u ofrecido al público un bien o servicio, si ha efectuado una relación de consumo en los términos anteriormente señalados, es decir, en tér- minos de verdadero desequilibrio frente al productor $\mathrm{y} / \mathrm{o}$ expendedor $\mathrm{y}$ el consumidor (Concepto No. 01085864 del 22 de noviembre de 2001).

En cuanto al criterio de existencia de desigualdad o desequilibrio entre los sujetos partes en las relaciones de consumo, la SIC ya lo había abordado en el concepto del año 1996, en donde había aludido a la desigualdad que existe entre consumidores productores en las relaciones de consumo, considerando que en dichas relaciones $s$ establecen vínculos entre un profesional y un lego, o no profesional; en el concepto de año 2001, modificó su postura al considera que el desequilibrio puede provenir de una elación donde ambas partes son profesionales pero una de ellas actúa por fuera de su esfera profesional. Sobre este cambio de posición de la SIC, Echeverri, Arango, Mesa, Peláez, Campillo y Ramírez (2012) afirman:

Para el año 2001, la SIC modificó su postura, lo que demuestra que este no ha sido un concepto pacífico, y sobre ello se hara hincapié en el estudio que se hace en esta ocasión; y lo hace para alejarse del concepto de destinatario final como presupuesto para la existencia de una relación de consumo, para afirmar que el fundamento de esta relación se basa en la existencia de una desigualdad o desequilibrio entre las partes. Si bien antes afirmaba que este se daba porque los sujetos de la relación eran un profesional y un no profesional, cambió su teoría al considerar que el desequilibrio puede provenir de una relación donde ambos son profesionales pero uno actúa por fuera de su esfera profesional; en otras palabras, la relación de consumo se presenta siempre y cuando exista una desigualdad en distintos temas, principalmente en lo que se refiere a la información. Lo anterior sin importar finalidad (p.10).

Entre los conceptos del año 1996 y el del año 2001, la SIC pasó de tener una concepción restringida de consumidor en la que el concepto de destinatario final era el que determinaba quién era consumidor, a una concepción amplia en la que el criterio del desequilibrio entre las partes era lo determinante sin importar la condición de las partes y el uso retendido. Sobre este cambio de postura de la SIC Villalba (2012) sostiene:

Según lo expresado por la SIC en este concepto, la noción de destinatario final no es fundamental en la definición de consum dor $y$ por el contrario el ámbito de aplicación de esta noción se hace extensivo en los casos en que a pesar de haberse adquirido con la finalidad de integrar en un proceso productivo o reincorporar al mercado sin transformar, se presentase un desequilibrio entre las partes. En este orden de ideas, se puede afirmar que la SIC pasó de tener una concepción restringida de consumidor en la que primaba el concepto de destinatario final y el uso personal o familiar, a una concepción más amplia en la que sin importar la condición de las partes y el uso pretendido, solamente importa el desequilibrio. Se admitirá en- tonces una relación de consumo entre dos profesionales o productores cuando se actúa fuera de la esfera de especialidad de alguno de ellos, caso en el que se presentaría el aludido desequilibrio derivado de la calidad de profano de uno de los contratantes frente al otro. Esta posición sin embargo no ha sido reiterada por esa entidad (p.86).

La Corte Suprema de Justicia también ha abordado el asunto de la noción de consumidor, en el año 2005 consideró que esta noción está ligada a la calidad de destinatario final y la adquisición de bienes y servicios con finalidad de darles uso privado, familiar, doméstica o empresarial, siempre y cuando no esté ligada a su actividad económica, es decir, la Corte acoge una concepción restringida de consumidor. Así las cosas, la Corte sostiene que es el concepto de consumidor final lo que determina la existencia de la relación de consumo. También incluye a las personas jurídicas en la noción de consumidor, en lo que no ha habido controversia en Colombia con respecto a ello.

En este orden de ideas, para estos efectos estima la Corte que, con estrictez, siempre será forzoso indagar en torno a la finalidad concreta que el sujeto -persona natural o jurídica- persigue con la adquisición, utilización o disfrute de un determinado bien o servicio, para reputarlo consumidor solo en aquellos eventos en que, contextualmente, aspire a la satisfacción de una necesidad propia, privada, familiar, doméstica o empresarial -en tanto no esté ligada 
intrínsecamente a su actividad económica propiamente dicha, aunque pueda estar vinculada, de algún modo, a su objeto social-, que es lo que constituye el rasgo característico de una verdadera relación de consumo. Este punto de vista, cabe resaltar, es el que puede identificarse en numerosos ordenamientos jurídicos que, como adelante se examinará, catalogan únicamente como consumidor a quien sea destinatario final del bien o servicio, o, por otro lado, exigen que la adquisición o utilización esté ubicada por fuera de la esfera de actividad profesional o empresarial de quien se dice consumidor; adicionalmene, no está de más anotar que una postura similar es la adoptada por la Superintendencia de Industria y Comercio cuando, entro de su competencia, ha conceptuado sobre el alcance del término que se viene estudiando (Sentencia del 03 de mayo de 2005, Exp. No. 5000131030011999 04421-01

Con respecto a la relación de consumo, la Corte precisó que esta no puede darse entre profesionales que actúan dentro de su esfera de especialidad, aunque se pruebe la existencia de un desequilibrio o asimetría en sus relaciones, es decir, el profesional que actúa dentro de la esfera de su profesión y que se encuentre en posición de debilidad no es considerado consumidor. En estos casos se aplica el régimen ordinario.

el hecho de que la relación entre las empresas demandante y demandada se haya presentado en el marco de su actividad profesional o empresarial, determina, en principio, que no haya lugar a presumir o entender que la sociedad actora se encontraba en una posición de debilidad económica, informativa, técnica o de cualquier otro orden; en todo caso, aun si se presentara cualquier asimetría o desequilibrio en una relación entre profesionales -que suele ocurrir-, ello no convertiría per se a la parte débil en consumidor, ni habilitaría la aplicación del régimen propi de ellos, toda vez que cualquier situación abusiva que pudiera darse o cualquier responsabilidad en la que pudiera incurrirse, como la derivada de productos defectuosos que aquí se ha invocado, no quedaría desamparada, sino que simplemente estaría sometida a las normas generales, que no a aquellas destinadas a los cons midores (Corte Suprema de Justicia, Sentencia del 03 de mayo de 2005, Exp. No. 5000131030011999-04421-01)

La Honorable Corte Suprema de Justicia ha mantenido esta concepción restringida de consumidor. En sentencia de 2009 reafirmó lo dicho en la Sentencia del 3 de mayo de 2005 al afirmar que es consumidor quien adquiere bienes con el fin de adquirirlos, usarlos o disfrutarlos para la satisfacción de una o más necesidades, vale decir, que no lo hace con fines empresariales o profesionales:

Se entiende por consumidor, conforme la definición contenida en el artículo 19 del Decreto 3466 de 1982, “[t]oda persona, natural o jurídica, que contrate la adquisición, utilización o disfrute de un bien o la prestación de un servicio determinado, para la satisfacción de una o más necesidades". Trátase, como ya tuviera oportunidad de precisarlo esta Corporación de un concepto que comprende: a) a toda persona, sea esta natural o jurídica; b) que requiera bienes muebles o inmuebles, sin distinción alguna; empero, para efectos de precisar los alcances la doctrina que aquí se expondrá, referida específicamente a la responsabilidad civil por productos defectuosos y no a otros aspectos de la protección a los consumidores, la Corte se circunscribe a examinar la cuestión en el estricto ámbito del consumidor de bienes muebles; c) con el fin de adquirirlos, usarlos o disfrutarlos para la satisfacción de una o más necesidades, vale decir, que no lo hace con fines empresariales profesionales, condición esta que lo hace merecedor de una especial tutela jurídica (Sent. 3 de mayo/05) (Corte Suprema de Justicia, sentencia del 30 de abril de 2009 Exp. No. 25899319399219990062901 ).

En el 2006, la SIC, después del pronunciamiento del 3 de mayo de 2005 de la Corte Suprema de Justicia, modificó su posición con respecto a la noción de consumidor, en esta oportunidad la SIC vuelve a acoger el criterio de destinatario final para definir la noción de consumidor; no siéndolo quien pretende incorporar el bien o servicio en un proceso productivo, o de transformarlo para que ingrese al mercado; reintroducirlo al mercado sin ser transformado, no destinarlo a la satisfacción de una necesidad propia o familiar.
Al respecto, es importante resaltar que, para la Superintendencia de Industria y Comercio, la satisfacción de necesidades a que se refiere el literal c, del Artículo $1^{\circ}$ del Decreto 3466 de 1982, está determinada en razón de la finalidad perseguida y la destinación del bien adquirido, o del servicio contratado, en tanto que no estén intrínsecamente ligadas a la actividad profesional o empresarial. Es así como es claro que quien adquiere un bien para incorporarlo en un proceso productivo, para transformarlo o utilizarlo a fin de obtener uno o más productos, o para comercializarlo, no es consumidor, en tanto que en estos casos la necesidad a satisfacer mediante la adquisición de dicho bien está intrínsecamente ligada a su actividad económica propiamente dicha. Sin embargo, en los casos en que el bien no sea destinado o utilizado para tales fines, y en los que, por lo tanto, no se puede excluir de tajo que exista una relación de consumo, la determinación de la existencia o no de esta debe realizarse con base en elementos de juicio adicionales, que son particulares a cada caso concreto (Superintendencia de Industria y Comercio, Concepto No. 05063562 del 13 de marzo de 2006).

El actual Estatuto del Consumidor o Ley 1480 de 2011 define al consumidor como toda persona natural o jurídica que, como destinatario final, adquiera, disfrute o utilice un determinado producto, cualquiera que sea su naturaleza para la satisfacción de una necesidad propia, privada, familiar o doméstica y empresarial cuando no esté ligada intrínse- 
camente a su actividad económica. Se enten- va de bienes y servicios. El productor según derá incluido en el concepto de consumidor el de usuario. El nuevo Estatuto del Consumidor acoge la concepción restringida de consumidor y los criterios expuestos por la Corte Suprema de Justicia y la SIC como el carácter de destinatario final, la satisfacción de necesidades privadas y la admisión de personas jurídicas como consumidor. Según Echeverri, Arango, Mesa, Peláez, Campillo y Ramírez, (2012)

Esta nueva definición de la ley trae consigo un componente objetivo y uno subjetivo; el primero hace relación al concepto de usuario o beneficiario, donde se me jora de manera evidente, pues en caso de presentarse una desigualdad puede reclamar quien use o disfrute el bien, $y$ no quien haya realizado el contrato, $y$ a concepto de destinatario final quien no puede transformar o comercializar el bien o servicio dentro de la relación de consumo. El segundo elemento, subjetivo, hace referencia a la necesidad, y no es otra cosa que la satisfacción de una necesidad propia o familiar, y que no se encuentre ligad intrínsecamente a su actividad económica (p.12)

\section{Productor}

Este concepto ha sido un tema más pacífico en la doctrina y en la jurisprudencia. La legislación colombiana sobre protección al consumidor distingue entre productor y proveedor, diferenciando estos dos que ocupan posiciones diferentes en la cadena productiel Estatuto del Consumidor es quien de manera habitual, directa o indirectamente, diseñe, produzca, fabrique, ensamble o importe productos. También se reputa productor quien diseñe, produzca, fabrique, ensamble importe productos sujetos a reglamento técnico o medida sanitaria o fitosanitaria. Por ejemplo, la compañía o sociedad que ensambla automóviles importados. Esa compañía sería un productor según el Estatuto de Consumidor.

\section{Proveedor}

Al igual que el concepto de productor, el concepto de proveedor también ha sido un tema pacífico en la doctrina y en la jurisprudencia el nuevo Estatuto del Consumidor lo define como a quien de manera habitual, directa o buya o comercialice productos con o sin ánimo de lucro. Por ejemplo, el concesionario que vende automóviles. Ese concesionario, según el Estatuto del Consumidor sería un proveedor.

El anterior Estatuto del Consumidor -Decreto Ley 3466 de 1982- también consagrab esos dos conceptos. Pero existe una diferencia entre las definiciones de productor $y$ proveedor o expendedor que consagró antiguo Estatuto y las que consagra el nuevo Estatuto del Consumidor, esa diferencia consiste en que en el nuevo Estatuto del Consumidor se introduce el elemento profesionalidad, a través de la expresión "quien de manera habitual", la cual no consagró el antiguo Estatuto del Consumidor. indirectamente, ofrezca, suministre, distri-

\section{Producto}

Otra definición que es importante para delimitar el concept la definición de producto, que no existía en el Decreto 3466 de 1982. El nuevo Estatuto del Consumidor define producto como todo bien o servicio, lo que quiere decir que cualquier bien ya sea mueble o inmueble o cualquier servicio puede ser objeto de la relación de consumo.

Con respecto a los bienes inmuebles, existía la discusión de que si se podían o no consumir este tipo de bienes. Esta discusión er suscitada por cuanto se asimilaba el concepto de consumidor con el de bienes consumibles. Los bienes consumibles son aquellos que se consumen o destruyen en su prime uso, lo que llevó a suponer que solo el que adquiría bienes muebles que se destruyeran con el primer uso era consumidor. Concebidas las cosas de esta manera, quien adquiriera bienes inmuebles no era considerado consumidor.

La discusión giraba alrededor de la posibilidad de asimilar la palabra consumidor con la expresión bienes consumibles, que trae la legislación civil. Se entiende que son bienes consumibles aquellos que se destruyen con su primer uso. En ese sentido, solamente podría ser consumidora persona que adquiriera bienes muebles que se destruyeran con el primer uso de ellos, de tal manera que se entendía que quien adquiría bienes inmuebles o fuese destinatario de servicios no era consumi-

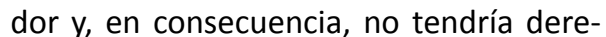
cho a la protección especial (Echeverri, Arango, Mesa, Peláez, Campillo \& Ramírez, 2012, p.20).

El Decreto 3466 de 1982 o antiguo Estatuto del Consumidor no hacía alusión alguna a la protección de los consumidores de bienes inmuebles. El nuevo Estatuto del Consumidor, a diferencia del antiguo Estatuto del Consumidor, sí le otorga protección jurídica a los adquirientes de bienes inmuebles. Esta protección se puede apreciar en el numeral 17 del artículo 5, que define lo que ha de entenderse como producto defectuoso, en el que expresamente se acepta que en dicha clasificación pueden incluirse los inmuebles que no ofrezcan la seguridad que el consumidor puede razonablemente esperar. De igual manera, en el Inciso final del artículo 8 de dicho Estatuto, se establece el término de la garantía legal para los inmuebles, de 10 años para la estabilidad de la obra, y de un año para sus acabados.

Ventajas comparativas en la aplicación del Estatuto del Consumidor con respecto a las normas de Derecho Comercial

Son varias las diferencias que existen en la aplicación del Estatuto del Consumidor con respecto a la legislación comercial. Como primera medida, hay que destacar que la legislación comercial es una legislación que está concebida para proteger los derechos de los productores y proveedores. El Estatuto del Consumidor tiene ventajas significativas con respecto al Derecho Comercial en lo 
que respecta a la protección de los derechos de los consumidores. El Estatuto del Consumidor reconoce una serie de derechos y deberes a favor de los consumidores, derechos que el Derecho Comercial no reconoce a los consumidores; el Estatuto del Consumidor garantiza de una manera más eficiente la calidad, idoneidad y seguridad de los productos, constituyéndose estos en un deber de los productores y proveedores cuyo incumplimiento genera responsabilidades solidarias entre productores y proveedores por garantía frente a los consumidores, responsabilidad administrativa ante las autoridades de control y responsabilidad por daño por producto defectuoso ante los consumidores, el Código de Comercio no contempla estas responsabilidades por el incumplimiento de los deberes de calidad, idoneidad y seguridad por parte de los productores y proveedores; el Estatuto del Consumidor establece la responsabilidad por daño por producto defectuoso que se origina cuando un producto defectuoso cause lesiones personales o muerte a una persona o cause daño a otros bienes diferentes, para que se configure esta responsabilidad, el consumidor deberá de mostrar el defecto del bien, el daño y nexo causal; el Estatuto del Consumidor regula la publicidad, la cual tendrá un carácter vinculante, la legislación comercial no regula la publicidad en pro de la defensa de los consumidores; el Estatuto del Consumidor regula las cláusulas abusivas prohibiendo este tipo de cláusulas a favor del consumidor, de igua manera regula los contratos de adhesión, los cuales deben cumplir con una serie de condiciones mínimas, a diferencia del Código de
Comercio que no regula estos aspectos; también el Estatuto del Consumidor consagra a favor de los consumidores una serie de acciones jurisdiccionales para la defensa de sus derechos, ya sea como derechos colectivos como derechos subjetivos patrimoniales, acciones que se ventilarán a través de procesos breves y rápidos que garanticen una pronta solución de los conflictos, a diferencia de Código de Comercio que establece acciones que exigen muchos requisitos y que se ventilan por medio de procesos largos y paquidérmicos.

\section{Algunas relaciones que siendo comerciales} DE CONSUMO no son reguladas por el Estatuto del Consumidor

Existen relaciones que siendo de consumo no son reguladas por el Estatuto del Consumidor; esto debido a que el mismo Estatuto señala que su aplicación es suplementaria en los sectores donde no exista una regulación especial. Tenemos entonces que el Estatuto del Consumidor se aplica de manera genera en todos los sectores de la economía que carezcan de una legislación especial de protección al consumidor.

En Colombia, con posterioridad a la expedición de la Constitución de 1991, se han adoptado diversas leyes tendientes a proteger a los consumidores, es decir, el régimen legal de protección a los consumidores nacionales es disperso. Este régimen legal disperso de protección al consumidor se debe en gran parte, a la trascendencia económica y social que tienen algunos sectores o actividades económicas para el Estado, y que por ende, demandan de una mayor intervención y regularización de su parte, lo cual ha conllevado a establecer para esos sectores o actividades una legislación especial.

Dentro de esas relaciones jurídicas que siendo de consumo no son reguladas por el Estatuto del Consumidor, están: Las relaciones jurídicas de las EPS con sus usuarios, las cuales están sujetas a la Ley 100 de 1993; las relaciones jurídicas de las empresas de servicios públicos domiciliarios con los usuario de dichos servicios, las cuales están reguladas por la Ley 142 de 1994; las relaciones jurídicas mediante las cuales se celebran contratos de arrendamiento de vivienda urbana las cuales están reguladas por la Ley 820 de 2003; las relaciones jurídicas de los consumidores financieros con las entidades pertenecientes a dicho sector, como los bancos, aseguradoras y bolsas de valores, estas relaciones se regulan por la Ley 1328 de 2009; las relaciones jurídicas que se originan en torno al sector de las Tecnologías de la Información y las Comunicaciones, se regularán por la Ley 341 de 2009; las relaciones jurídicas derivadas de la prestación de los servicios postale se regularán por la Ley 1369 de 2009; las relaciones jurídicas derivadas de la prestación de servicios turísticos se regularán por la Ley 1558 de 2012 y las relaciones jurídicas que se derivan en las bases de datos 0 archivos se regularán por la Ley 1581 de 2012.

\section{CONCLUSIÓN}

de Consumo no se les aplica el Estatuto de nuevo Estatuto del Consumidor ha deter- Consumidor, ello se debe al régimen disperminado como criterio objetivo para su apli- so de protección al consumidor que hay en 
Colombia; algunas relaciones de consumo tienen una legislación especial debido a la importancia de ciertos sectores económicos.

\section{REFERENCIAS}

Echeverri, V., Arango, D., Mesa, J., Peláez, R., Campillo, C. \& Ramírez, R. (2012). Foro del jurista, una mirada a la Ley 1480 de 2011. Cámara de Comercio de Medellín. Medellín, Colombia: Tragaluz Editores S.A.S.

Giraldo, Caycedo \& Madriñán (2012). Comentarios al nuevo Estatuto del Consumidor. Bogotá, Colombia: Legis.

Ossa, D. (2010). Protección, garantía y eficacia de los derechos del consumidor en Colombia. Revista Facultad de Derecho y Ciencias Políticas, 40(112), 203-239.

Villalba, J. (2012). Introducción al derecho del consumo. Bogotá, Colombia: Universidad Militar Nueva Granada.

\section{NORMATIVIDAD}

Corte Suprema de Justicia, Sala de Casación Civil, Sentencia del 03 de mayo de 2005, Exp. No. 5000131030011999-04421-01, M.P. César Julio Valencia Copete.

Corte Suprema de Justicia, Sala de Casación Civil, Sentencia del 30 de abril de 2009. Exp. No. 258993193992199900629 01, M.P. Pedro Octavio Munar Cadena.

Ley 1480 de 2011 . Artículo 2.

Superintendencia de Industria y Comercio, Concepto No. 96027242 de septiembre 2 de 1996.

Superintendencia de Industria y Comercio, Concepto No. 01085864 del 22 de noviembre de 2001.

Superintendencia de Industria y Comercio, Concepto 03025237 del 09 de mayo de 2003.

Superintendencia de Industria y Comercio, Concepto No. 05063562 del 13 de marzo de 2006. 